\title{
Energy Scheduling of Residential Appliances by a Pigeon-Inspired Algorithm under a Load Shaping Demand Response Program
}

\author{
Sandeep Kakran ${ }^{1}$ and Saurabh Chanana ${ }^{2}$ \\ ${ }^{1,2}$ Department of Electrical Engineering, National Institute of Technology, Kurukshetra, \\ India ${ }^{1}$ skakran@gmail.com, ${ }^{2}$ s_chanana@ rediffmail.com
}

\begin{abstract}
In this paper, an energy management system (EMS) is modelled in a novel way, for the scheduling of interruptible and uninterruptible appliances of a residential consumer. It is considered that the local renewable energy is generated by the rooftop PV panels installed at the home, to convert a consumer into a prosumer. An energy controlling unit (ECU) schedules the home appliances according to the price signals received from the utility company within the user preferred durations so that the cost of electricity consumption could be minimized. A novel delay factor is also modelled to maintain the comfort level of the consumer. It is assumed that the consumer participates in a demand response (DR) program, based on real time price combined with inclined block rate (RTP-IBR) pricing scheme. Due to this, the peak to average ratio (PAR) of power is decreased and maintained within the satisfactory limits. Finally, for the optimization of the formulated objective function, a pigeon-inspired optimization (PIO) algorithm is used, due to its effectiveness and fast convergence rate over the other similar algorithms. At the end, the results of energy scheduling have been compared and verified against the results achieved by the particle swarm optimization (PSO) algorithm.
\end{abstract}

Keywords: Smart grid; demand response; energy management system; real time price combined with inclined block rate; pigeon-inspired optimization.

\section{Introduction}

Smart grid is a fast growing system, having advance technologies for the measurement of the network parameters and advanced metering infrastructure (AMI) for the two-way communication of the useful information in the network [1]. A rapid growth in the small-scale distributed generation has been also observed in the recent time due to the smart grid technology. Small level energy consumers have started active participation in the energy management programs, due to advance tools of the smart grid. Demand response (DR) programs are the main tools of the smart grid, which encourage the energy consumers to actively participate in the energy market [2-4].

The design and implementation of an efficient DR program in a system is an important task to be performed very carefully [5]. Designing of different DR programs may be achieved by dividing it into different categories, like incentive based DR programs [6], price based DR programs [7,8], energy scheduling based DR programs [9]. In the energy scheduling based DR programs, the energy controlling unit (ECU) of the residential energy management system (EMS) schedule the appliances towards the low price time to give the benefit to the consumer in terms of savings in the electricity bill and to the utility company by reducing load demand during high-energy demand [10]. In recent years, many models of residential EMS and energy scheduling problems have been proposed by the researchers [11-13]. But still there is a requirement of an EMS model, which could fulfil maximum needs of the consumers as well as the utility company.

While doing research about a residential EMS, a researcher need to think about all important factors related to the residential EMS system. The main factors related to the residential EMS are taking care of consumer's comfort level by making sure the availability of appliances as soon as possible, in their given preferred duration, taking care of benefit of the utility company by applying techniques for the reduction of energy peaks on demand curve, selection of algorithm, which could give more accurate results, energy scheduling of residential appliances to minimize

Received: January $4^{\text {th }}, 2018$. Accepted: March $11^{\text {st }}, 2019$

DOI: 10.15676/ijeei.2019.11.1.2 
the cost of electricity consumption by choosing a real time pricing scheme, which will always give better result as compare to other conventional electricity tariffs. The mentioned factors are easy to implement, if they are implemented alone or in combination of two factors. But till now, the researchers have not explored all these factors in a common model of residential EMS. Some researchers have focused on real-time optimization algorithms for the reduction of energy consumption cost. They framed linear problems, which are easy to solve. However, they compromised with the comfort level of the consumers during their electricity cost minimization [14-16]. Local photovoltaic (PV) generation based residential EMS has been optimized using simulated annealing method in [17]. In [18], the authors considered shiftable loads, thermostatically controlled loads, electric vehicle (EV) and a local renewable energy source in a home EMS and they optimized the schedule of the appliances using evolutionary algorithm. A multi-objective model for the reduction of electricity cost and energy peaks by considering user satisfaction is solved in [19]. In [17-19], the authors optimized their models under time-of-use tariff and hence the scope of the real time scheduling of the EMS under real time price combined with inclined block rate (RTP-IBR) pricing scheme can be seen in these papers. In [20], the authors optimized the electricity consumption cost of the households under DR programs based on changing price signals. In [21], the authors considered EV and energy storage system during the development of the load commitment strategy of smart home. But, the authors have not considered anything for the reduction of energy peaks in [20, 21]. In [22, 23], the authors used EV for load shaping purpose. The authors in [24] worked on the peak load shaping DR programs for the home EMS in a smart household. However, the authors have not worked on the reduction of daily energy consumption cost with the changing price of electricity in [22-24]. Some researchers focused only on the reduction of energy consumption of the consumers by the scheduling of appliances $[25,26]$. However, in such type of energy scheduling, a waiting time will appear in the operation of the appliances, which will affect the comfort level of the consumers.

Among all factors of residential EMS, pricing schemes and solution algorithms play a key role in the success of energy management programs. Pricing schemes are main tool of demand response programs and hence, they are very essential to encourage the consumers to participate in the energy management programs to reduce their cost of electricity consumption. Algorithms are related to the solution of the model of the energy management programs. A fast algorithm with more accurate results is always preferred, while solving such problems. Latest energy scheduling methods having different pricing schemes and communication techniques are reviewed in [27] by presenting DR algorithms for the residential area. In [28] an energy management model is proposed for the scheduling of home appliances under time-of-use pricing. The authors optimized the model by using genetic algorithm. In [29] the authors presented another home EMS for the scheduling of household appliances and PV source under day-ahead market price. They used clonal selection algorithm for the optimization of the model. In [28, 29], authors did not consider automatic appliances, consumer comfort and advance real time pricing scheme, which could definitely improve the results in real time. A robust optimization model is proposed in [30] for the household load scheduling considering the intermittency in the household PV system. Authors framed a quadratic model to solve the energy scheduling problem and they tested the problem on feed-in tariff. Authors in [31] proposed a mixed integer programming based game theoretic algorithm for the solution of consumption scheduling problem. The limitations of the game theory approaches are that these algorithms sometimes deviate from the actual situations and the solution become more complex with the increase of variables. By considering different pricing schemes and by proposing different solution algorithms for the solution of energy scheduling problems, the authors provided a path for the implementation of advance real time pricing schemes and other optimization approaches for the scheduling of automatic home appliances, peak load management and user comfort management. In this paper, a residential EMS model is proposed to minimize the cost of electricity consumption by the scheduling of commonly used interruptible and uninterruptible appliances. To receive the maximum benefits from the system the consumer act as a prosumer by selling 
extra locally generated solar energy to the grid. A model of solar energy generation is also presented in the paper. The purpose of the energy scheduling problem is not only the minimization of the cost of electricity consumption, but at the same time, it has to maintain the comfort level of the consumer. Hence, to maintain the satisfaction level of the consumer, a delay factor has been also proposed in the paper. For the appliance scheduling, RTP-IBR pricing based DR program is used. With the inclusion of this pricing scheme the peak to average ratio (PAR) value is reduced within satisfactory limits, which in turn helps in the reliability maintenance of the system. Peak load management is one of the main requirement of the utility companies. Hence by improving PAR value, this paper provides a significant contribution in this field. Finally, with the help of proposed energy scheduling model, the electricity consumption cost and PAR value have been minimized using pigeon-inspired optimization (PIO) on a time horizon of 96-time slots (each of 15-minutes duration) and improvement of the results has been verified by comparing them with the results of particle swarm optimization (PSO).

The remaining paper is organized as follows: The system architecture of a residential EMS has been discussed in section-II in detail. Modelling of different types of appliances, dynamic pricing schemes and the model of solar energy has also been included in this section. Proposed solution approach is discussed in section-III. Problem formulation, delay cost and PIO used for the simulation in the paper have been also discussed in this section. Case study and the simulation results have been shown and discussed in section-IV. Effect of the delay factor has been also discussed in this section. Concluding remarks have been included in section-V.

\section{System Architecture}

\section{A. Energy Management System}

A residential energy management system is required to manage the electricity consumption of home appliances. It provides an infrastructure to the residential consumers to participate in a DR program. It comprises AMI, smart meter (SM), ECU, home appliances, internet units to connect various equipment and display units at home. A model of a residential EMS is shown in Figure. 1.

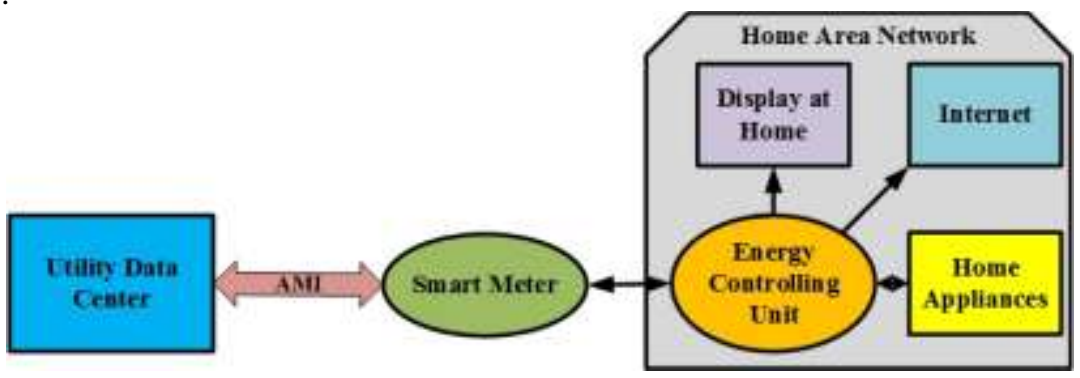

Figure 1. A residential energy management system

AMI provides two-way communication facilities in EMS architecture. Information about electricity price from the utility company is transmitted to the smart meter for appliance scheduling and energy scheduling data is transferred from SM to the utility company by AMI. In this way, an important role is played by AMI in EMS architecture. Smart meters are installed next to AMI. Energy consumption data reading and processing is done by SM to the utility company, while it also processes energy price data to the ECU.

It has been assumed that the house is equipped with interruptible and non-interruptible appliances. Price signals and energy consumption data can be seen at in-house display device at any time. To transmit the signals between different devices in home area network various techniques like z-wave, ZigBee, Wi-Fi etc. can be used.

\section{B. Appliances modelling}

In this paper, a home is assumed, having $A$ number of commonly used interruptible and uninterruptible appliances. Energy scheduling of the appliances is done by an energy-controlling 
unit. ECU schedules the appliances on complete time horizon, i.e. 24 hours in our case. It is assumed that a full day is divided into 96-small time slots, each of 15-minutes duration. If $H$ is the set of 96 small time slots then it can be seen as $H=[1,2, \ldots \ldots \ldots . .96]$. Hence the smallest length of operation time of any appliance can be 15-minute. Energy consumption scheduling vector of each appliance $a$ is denoted by $Z_{a}$. Hence,

$$
Z_{a} \triangleq\left[Z_{a}^{1}, Z_{a}^{2} \ldots \ldots \ldots \ldots \ldots \ldots \ldots Z_{a}^{96}\right]
$$

where $Z_{a}^{h}$ denotes energy consumption by appliance $a$ at time slot $h$. Further, let us assume $E_{a}$ is the total energy required for the completion of operation of appliance $a$. Hence

$$
\sum_{h \in H} Z_{a}^{h}=E_{a} \quad \forall a \in A
$$

Any appliance $a \in A$ can have different energy requirement for the completion of the task. The energy requirement of an appliance depends on its operational characteristics and the way in which it is used. For example, a clothes dryer needs total $5.5 \mathrm{kWh}$ energy to complete its task in 4-time slots, similarly a personal computer need $0.4 \mathrm{kWh}$ energy to complete its task in 16-time slots. Different appliances have different operational characteristics. In this paper, following type of appliances have been considered: -

- Type-1: In this category, the interruptible appliances are included. These appliances can run in any time slot in user's preferred duration. These can operate only in ON or OFF status. In ON condition, these consume a fixed energy level of $Y_{a}^{\max }$ and in OFF condition, energy consumption level become zero. Hence energy consumption of these appliances can be given as

$$
Z_{a}^{h}=Y_{a}^{\max } \quad \forall a=\text { interruptible } \in A, \forall h \in H
$$

In this paper, it has been that the user preferred duration for the interruptible appliances is divided into some sub-durations in such a way that each interruptible appliance run one time in each sub-duration. Along with this, it is assumed that each interruptible appliance runs continuously for 2-time slots after getting $\mathrm{ON}$ in any sub-duration i.e. it operates as an uninterruptible appliance in a sub-duration.

- Type-2: In this category, uninterruptible appliances are included. Uninterruptible appliances may be of two types, 1) with constant load profile, 2) with the variable load profile. In this paper, it has been assumed that each uninterruptible appliance has a variable load profile with the energy level of $X_{a}^{h}$. Hence energy consumption of these appliances can be given as

$$
Z_{a}^{h}=X_{a}^{h} \quad \forall a=\text { uninterruptible } \in A, \forall h \in H
$$

If the operation time of any appliance in this category is more than 15-minutes to complete its task, then the length of operation time of the appliance should be integer multiple of 15minutes or it can be greater than and nearest number to the actual length of operation time of the appliance. For example, if an appliance need 9-minutes to complete a task then the length of operation time for this should be set as 1 . If any other appliance needs 42 -minutes to complete its task, then the length of operation time for this appliance should be set as 3 (because $15 * 3=45$ is the multiple number of 15 and it is nearest to the operation time of the appliance).

\section{Pricing Schemes}

Pricing schemes are fixed by the utility company for its consumers. In general, there are two types of pricing schemes, 1) static pricing scheme 2) dynamic pricing scheme. In static pricing scheme, generally the price of electricity remains same within the complete energy-planning 
horizon. On the other side, in the dynamic pricing scheme, the price of electricity changes frequently, according to the electricity market conditions [32]. Time-of-use pricing scheme, critical peak pricing scheme, real time pricing (RTP) scheme and RTP-IBR scheme are the pricing schemes under dynamic pricing category. In this paper, RTP-IBR scheme has been considered for the energy scheduling of the appliances.

\section{- Real Time Pricing combined with Inclined Block Rate}

In the RTP pricing scheme, generally the price of electricity changes after every hour based on the real time status of the electricity market and remain same for any time slot. However, in the RTP-IBR dynamic pricing scheme, the price of electricity can be different within the same time slot. For example, if the user wants to reduce his electricity consumption cost, then he plans to run the appliances at a low price time. Due to this, the total energy consumption at that time may exceed the threshold value of the inclined block rate (IBR) and the energy consumption cost rises to a value higher than the expected. In this paper, two levels of the electricity price in RTPIBR scheme have been considered and the price changes at every hour. If it is assumed that, $Z_{h}$ is the total energy consumption and $\gamma_{h}$ is the threshold value of energy consumption at $h$ time slot then the price function will be as follows:

$$
P_{h}\left(Z_{h}\right)=\left\{\begin{array}{lr}
\alpha_{h}, & \text { if } 0 \leq Z_{h} \leq \gamma_{h} \\
\beta_{h}, & \text { if } Z_{h}>\gamma_{h}
\end{array}\right.
$$

where $\alpha_{h}$ is the first real time electricity price level at $h$ time slot and $\beta_{h}$ is the second real time electricity price level at $h$ time slot. In RTP-IBR scheme, value of $\beta_{h}$ should be always greater than $\alpha_{h}$ in each time slot. To ensure this, it is assumed that

$$
\beta_{h}=\lambda . \alpha_{h}
$$

where $\lambda$ is a positive value such that $\lambda>1$. From equation (6), it can be said that the value of $\beta_{h}$ changes with $\alpha_{h}$. It means, when the value of $\alpha_{h}$ is the lowest then the value of $\beta_{h}$ will be the lowest. This ensures the high responsiveness of demand within a time slot.

\section{Renewable Energy Source}

In the scheduling of appliances, a small distributed renewable energy source has been also considered in form of rooftop PV panels. The capacity of rooftop PV panel may vary, depending on the number of installed PV panels. It has been assumed that PV panels of $1 \mathrm{~kW}$ capacity have been installed on rooftop of the consumer. Solar irradiation and temperature data are taken from [33] and are shown in Figure. 2. Power generation by the PV panels is governed by following equation:

$$
P V^{h}=\left(\frac{f_{P V}}{0.8}\right) \cdot P V_{\text {rated }} \cdot \frac{G_{h}}{G_{S T C}} \cdot\left\{1+\alpha_{T}\left(T_{h}-T_{S T C}\right)\right\}
$$

where $P V^{h}$ is the actual power generated by the PV panel (in $\mathrm{kW}$ ) at $\mathrm{h}^{\text {th }}$ time slot, $P V_{\text {rated }}$ is rated power of the PV panel (in $\mathrm{kW}$ ), $f_{P V}$ is the factor to include effect of dust etc., $G_{h}$ is the actual radiation (in $\mathrm{W} / \mathrm{m}^{2}$ ) from the Sun at $\mathrm{h}^{\text {th }}$ time slot, $T_{h}$ is the actual temperature (in ${ }^{\circ} \mathrm{C}$ ) at $\mathrm{h}^{\text {th }}$ time slot, $G_{S T C}=1000 \mathrm{~W} / \mathrm{m}^{2}, T_{S T C}=25^{\circ} \mathrm{C}$ and $\alpha_{T}=-0.0048^{\circ} \mathrm{C}$. 


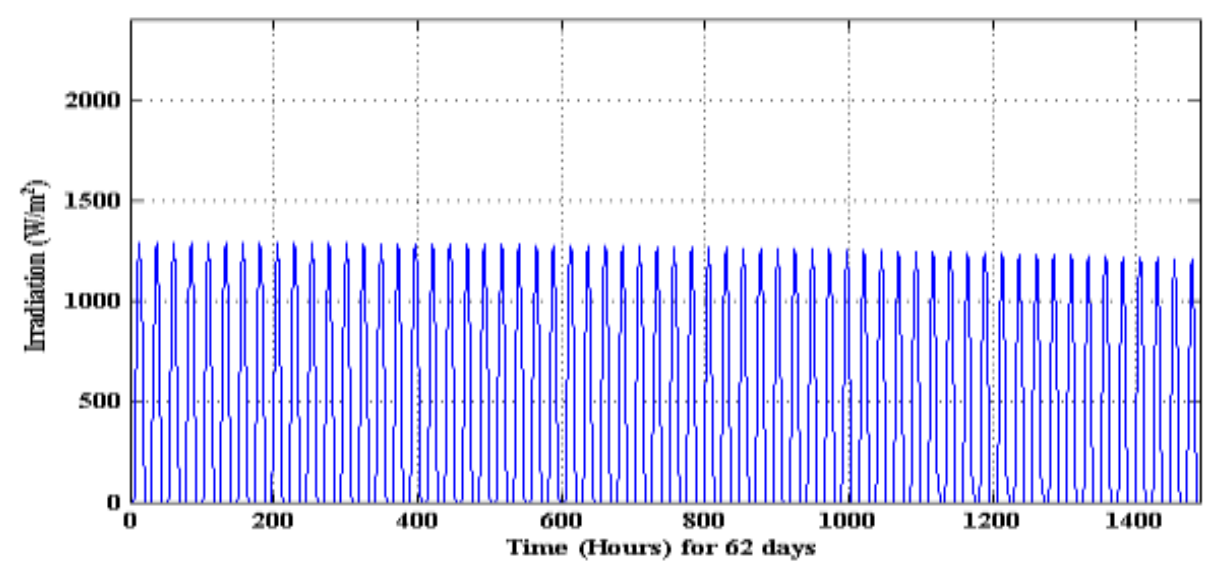

(a)

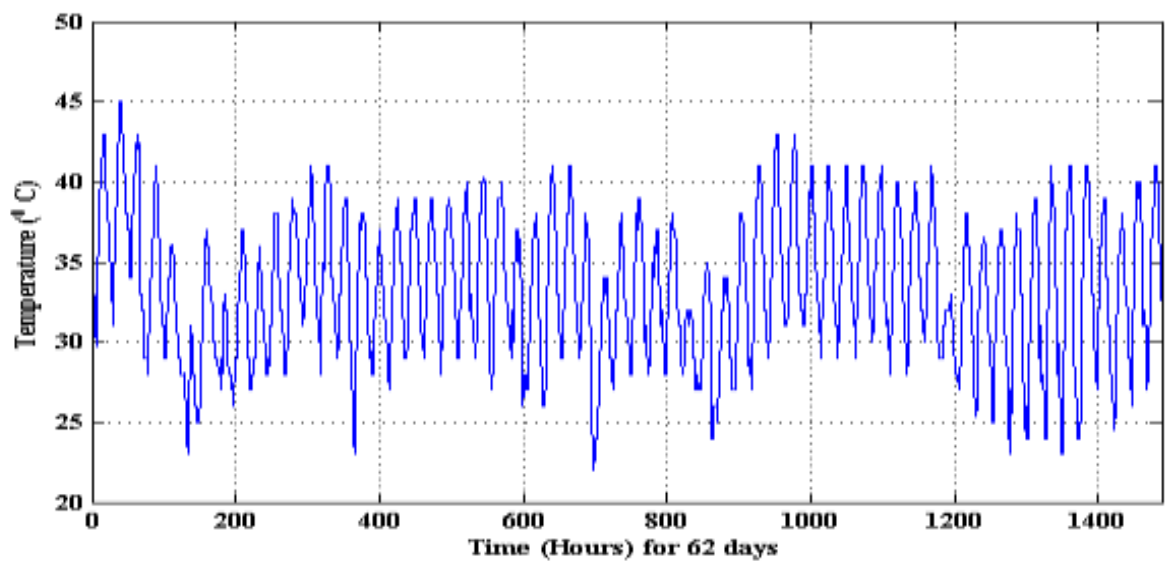

(b)

Figure 2. Meteorological data. (a) Hourly solar irradiation, and (b) hourly temperature.

\section{Problem Formulation and Solution Approach}

For the scheduling of specified home appliances, it is necessary for the users to define some parameters in advance for the appliances. For the interruptible appliances, it is necessary to set the start and end time of each sub-duration of the appliances in the complete user preferred duration. Similarly, for the uninterruptible appliances, it is necessary to set the start and end time of the complete user preferred duration. Hence, it is assumed that $m_{a}, n_{a} \in H,\left(m_{a}<n_{a}\right)$ are the indexes to indicate the start and the end time slots, respectively, of a sub-duration for the interruptible appliances and of a user preferred duration for uninterruptible appliances. Along this operation interval, $l_{a}$ indicates the length of operation of the interruptible appliances in a sub-duration and of the uninterruptible appliances in a user preferred duration. Here it should keep in mind that $\left(n_{a}-m_{a}\right)$ should be greater than or equal to the length of the operation $\left(l_{a}\right)$ of appliance $a$. For example, if any appliance takes 10-time slots to finish its work then $\left(n_{a}-m_{a}\right)$ should not be less than 10. It means that it can be any number from 10 to 96 according to the requirement of any appliance by the user. In addition to this, energy consumption data of each appliance should be also known before starting energy scheduling. Hence, an energy consumption matrix $Z_{a}^{h}$ for the appliances can be defined as, 


$$
Z_{a}^{h}=\left\{\begin{array}{lr}
Y_{a}^{\max }, & \forall a=\text { interruptible } \in A, h \in\left[t_{a}, t_{a}+l_{a}\right] \\
X_{a}^{h}, & \forall a=\text { uninterruptible } \in A, h \in\left[t_{a}, t_{a}+l_{a}\right] \\
0, & \forall a \in A, h \in H \backslash\left[t_{a}, t_{a}+l_{a}\right]
\end{array}\right.
$$

here in matrix $Z_{a}^{h}$, each row contains the data of energy consumption of a certain appliance. Each column represents the time slot $h \in[1,96]$. In (8), a new variable $t_{a}$ has been also introduced. This variable defines the task starting time of appliance $a$ in a sub-duration for interruptible appliances and in a user preferred duration for uninterruptible appliances. The value of $t_{a}$ should be greater than or equal to $m_{a}$ and less than or equal to $\left(n_{a}-l_{a}\right)$. It means, the range of task starting time of $a$ is,

$$
t_{a}=\left[m_{a},\left(n_{a}-l_{a}\right)\right]
$$

For all appliances, task starting time variable matrix can be defined as,

$$
t=\left[t_{1}, t_{2}, \ldots \ldots \ldots t_{A}\right]
$$

So, for an appliance $a$ value of $m_{a}, n_{a}, l_{a}$ and $E_{a}$ are already known. $t_{a}$ is the only unknown variable that has to be calculated. Hence, after the calculation of matrix $t$, energy consumption vector of the appliances would be determined. Now, the cost of energy consumption can be defined as,

$$
\text { Cost }=\sum_{h}\left(\sum_{a} Z_{a}^{h}\right) \cdot P_{h}\left(\sum_{a} Z_{a}^{h}\right)
$$

here $P_{h}$ is the electricity price at time slot $h$, which is the function of energy consumption at time slot $h$ and can be determined using (5).

\section{A. Delay Cost}

A delay factor $\alpha_{a}^{h}$ has also been introduced in the paper, which is used to calculate the delay cost of any appliance $a$ at a time slot $h$. This is represented as,

$$
\alpha_{a}^{h}=\frac{\left(\delta_{a}\right)^{h-m_{a}}}{E_{a}} \quad \forall a \in A, \forall h \in\left[m_{a},\left(n_{a}-l_{a}\right)\right]
$$

Here, it is assumed that $\alpha_{a}^{m_{a}} \leq \ldots \ldots \leq \alpha_{a}^{\left(n_{a}-l_{a}\right)}$, which implies that the value of delay factor increases with the delay in the starting time of the appliance $a$ and $\alpha_{a}^{h}=0$ for all $h<m_{a}$ and $h>\left(n_{a}-l_{a}\right)$. In (12), $\delta_{a}$ is a control parameter for the delay factor. The value of delay factor increases with the increment of $\delta_{a}$. Now, the delay cost of appliance $a$ can be modeled as,

$$
\text { Delay Cost }=\sum_{h=1}^{H} \sum_{a=1}^{A} \alpha_{a}^{h} \cdot Z_{a}^{h}
$$

\section{B. Energy Scheduling Function}

By combining (11), (12) and (13), the final energy scheduling function can be defined as follows subject to $t \in\left[m_{a},\left(n_{a}-l_{a}\right)\right]$,

$$
F=\text { minimize } \sum_{h}\left(\sum_{a} Z_{a}^{h}\right) \cdot P_{h}\left(\sum_{a} Z_{a}^{h}\right)+\sum_{h=1}^{H} \sum_{a=1}^{A} \frac{\left(\delta_{a}\right)^{h-m_{a}}}{E_{a}} \cdot Z_{a}^{h}
$$

The first part in (14) is the total cost of energy consumption and the second part is delay cost of all the appliances. There is a trade-off involved in between the objectives shown in (14). It simply means that if the user wants lowest possible electricity bill, then he has to lose his comfort associated with the electrical appliances in terms of high delay cost and if the user wants full 
comfort from the electrical appliances then he has to compromise with high electricity bill. So, the energy scheduler schedules the appliances in such a way that both the electricity bill and the delay cost of the user could be maintained at the optimal point. Here, the value of parameter $\delta_{a}$ decides the level of trade-off between both the objectives. The value of parameter $\delta_{a}$ can be predetermined and the associated operation modes can be given as, i) high cost reduction, if $\delta_{a}=$ 1 ; ii) medium cost reduction, if $\delta_{a}>1$; and iii) no cost reduction, if $\delta_{a} \gg 1$.

\section{- Inclusion of Renewable Energy Source}

With the inclusion of renewable energy source i.e. solar energy, the consumer will have two supply sources at a time. One is supply from the grid and the other is supply from PV panel. If at any time of the day, renewable energy generated by PV panels is higher than the consumer demand at that time, then the extra renewable power can be fed back to the grid, which again gives benefit to the consumer by further reducing their electricity bill. If the energy generated by PV panels is less than the consumer demand at any time, then the remaining electricity will be consumed from the grid. It has been assumed that the power generated by the PV panels is fed to the grid with the same tariff, on which the grid power is purchased. This feature shows the direct involvement of the user in the electricity market as a prosumer and it helps in the minimization of the cost of electricity. With the inclusion of PV energy, the objective function will be modified as follows subject to $t \in\left[m_{a},\left(n_{a}-l_{a}\right)\right]$,

$$
F=\text { minimize } \sum_{h}\left(\sum_{a} R_{a}^{h}\right) \cdot P_{h}\left(\sum_{a} R_{a}^{h}\right)+\sum_{h=1}^{H} \sum_{a=1}^{A} \frac{\left(\delta_{a}\right)^{h-m_{a}}}{E_{a}} \cdot Z_{a}^{h}
$$

here $R_{a}^{h}$ is a variable, which represents the remaining demand of appliance $a$ at time slot $h$, left after the utilization of energy generated by rooftop PV panels and has to be fulfilled by the grid at price $P_{h}$. Variable $R_{a}^{h}$ can be defined as,

$$
R_{a}^{h} \geq \sum_{a \in A} Z_{a}^{h}-(P V)^{h} \quad \forall h \in H
$$

here $(P V)^{h}$ denote the energy generated by the rooftop PV panels at $h^{\text {th }}$ time slot.

\section{Solution Approach: Pigeon-Inspired Optimization}

Pigeon-inspired optimization algorithm is a bio-inspired algorithm based on pigeon initialization. The basic PIO has two main operators [34], i) map and compass operator, ii) landmark operator. The first operator is based on sun and magnetic field and the second operator is based on landmarks. By the rule of map and compass operator, each pigeon will have a velocity and a position in the selected space, which are updated dynamically using the global best $\left(\mathrm{G}_{\text {best }}\right)$ solutions found. Let in a D-dimensional space with the $N$ number of pigeons, the velocity vector is $V_{i}=\left[V_{1 d}, V_{2 d}, V_{3 d}, \ldots \ldots, V_{i d}\right]$ and their corresponding position vector is $X_{i}=\left[X_{1 d}, X_{2 d}\right.$, $\left.X_{3 d}, \ldots \ldots, X_{i d}\right]$ where $i=1,2,3 \ldots . . N$, then after getting the value of $G_{b e s t}$, the pigeon velocity and position are updated in each iteration using the following equations:

$$
\begin{aligned}
& V_{i d}(t+1)=V_{i d}(t) * e^{-(R * i t e r)}+\operatorname{rand} *\left(G_{b e s t}-X_{i d}(t)\right) \\
& X_{i d}(t+1)=X_{i d}(t)+V_{i d}(t+1)
\end{aligned}
$$

where $R$ is map and compass factor in the range of [0-1], $\operatorname{rand}()$ is the function used to generate random number and $G_{\text {best }}$ is the current global best position.

In the nature, the pigeons change their strategies near the destination point. They use landmark operator in place of map and compass operator, as the guidance tool near the destination. Using the landmark operator, the convergence speed of the PIO algorithm improves. As compared to the other similar algorithms, the implementation of PIO is very easy. The PIO algorithm has fast convergence speed as compare to the PSO algorithm. The PSO algorithm 
sometimes trap into some local optimal solution during the solution of the complex problems, while the PIO algorithm shows an effective improvement in this regard.

\section{Case Study and Simulation Results}

For the energy scheduling of the home appliances, sixteen types of commonly used appliances have been considered. Each appliance can be used one or more times in a day, according to the user requirements. It means that the user preferred duration for each appliance can be defined one or more times on the complete time horizon. Interruptible appliances must be scheduled once in each sub-duration. It is assumed that there is not any priority given to any appliance during energy scheduling. Detail information of the appliances has been shown in Table 1. The value of $\lambda$ has been taken from [35] and is equals to 1.5. We have assumed threshold power $\gamma_{h}=1.0$. For the optimization of objective function using PIO, the population size, $\mathrm{N}_{\mathrm{p}}$ is 500. The optimization algorithm runs for $I=25$ iterations. Other used parameters have been shown in Table 2 . The complete problem has been solved and results have been determined using MATLAB software.

\section{A. Trade-off between Electricity Consumption Cost and Delay Cost}

To achieve minimum electricity bill, the appliances must run according to the schedule given by ECU. By doing so, comfort level of the user may be decreased. So, if the user wants high comfort level, then he may get a huge increment in the electricity bill. It means there is a tradeoff involved between the electricity consumption cost and the delay cost. To check the impact of the delay factor on electricity consumption cost, a new term average delay time $\left(D T_{\text {avg }}\right)$ of all appliances is defined as follows,

$$
D T_{\text {avg }}=\frac{\sum_{a}\left(t_{a}-m_{a}\right)}{\sum a\left(n_{a}-l_{a}-m_{a}\right)}
$$

The simulation results of the relationship between the electricity consumption cost and $D T_{\text {avg }}$ is shown in Figure. 3. It is clear from the Figure that the electricity consumption cost is the highest when value of $D T_{\text {avg }}$ is zero. It means, in this case, the user's major concern is to reduce the delay time. With the increase in value of average delay time, the electricity consumption cost decreases and reaches to the minimum value, when $D T_{\text {avg }}=0.3811$ i.e approximately $38 \%$. Here, the impact of control parameter $\delta_{a}$ can also be analyzed. As the value of control parameter is increased from $\delta_{a}=1$ to $\delta_{a}=2$, the energy consumption cost increases from 52.19 cents to 70.71 cents, while the average delay time decreases from $38.11 \%$ to only $0.60 \%$.

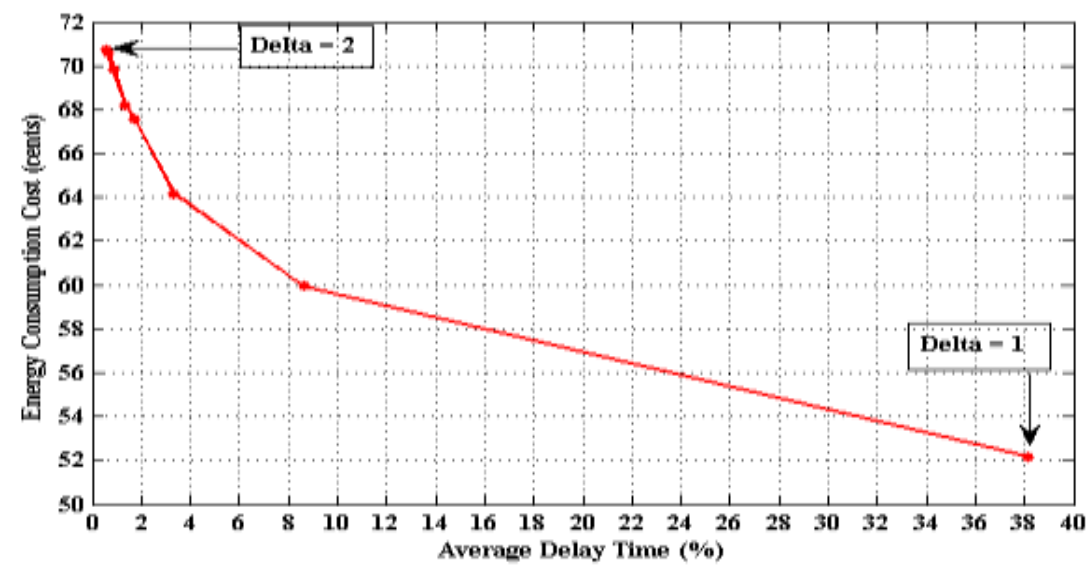

Figure. 3 Trade-off between electricity consumption cost and delay cost 
Sandeep Kakran, et al.

Table 1. Parameters of Automatic Appliances used in the Simulation

\begin{tabular}{|c|c|c|c|c|c|c|}
\hline S.No. & Appliance & $\begin{array}{l}\text { Operation } \\
\text { Duration }\end{array}$ & $\begin{array}{c}\text { Operation } \\
\text { Sub- } \\
\text { duration }\end{array}$ & $\begin{array}{l}\text { Operating } \\
\text { slots }\end{array}$ & $\begin{array}{c}\text { Energy } \\
\text { demand/ } \\
\text { slot }(\mathrm{kWh})\end{array}$ & $\begin{array}{c}\text { Total } \\
\text { energy } \\
\text { demand } \\
(\mathrm{kWh})\end{array}$ \\
\hline 1 & Humidifier & $1-24$ & - & 8 & 0.0125 & \multirow{2}{*}{0.2} \\
\hline 2 & Humidifier & $73-96$ & - & 8 & 0.0125 & \\
\hline 3 & $\begin{array}{c}\text { Air } \\
\text { conditioner }\end{array}$ & $1-24$ & - & 8 & 0.25 & \multirow{2}{*}{4} \\
\hline 4 & $\begin{array}{c}\text { Air } \\
\text { conditioner }\end{array}$ & $49-72$ & - & 8 & 0.25 & \\
\hline 5 & PHEV & \multirow{6}{*}{$1-32$} & $1-5$ & 2 & 0.825 & \multirow{8}{*}{13.2} \\
\hline 6 & PHEV & & $6-10$ & 2 & 0.825 & \\
\hline 7 & PHEV & & $11-15$ & 2 & 0.825 & \\
\hline 8 & PHEV & & $16-20$ & 2 & 0.825 & \\
\hline 9 & PHEV & & $21-25$ & 2 & 0.825 & \\
\hline 10 & PHEV & & $26-32$ & 2 & 0.825 & \\
\hline 11 & PHEV & \multirow{2}{*}{$81-96$} & $81-88$ & 2 & 0.825 & \\
\hline 12 & PHEV & & $89-96$ & 2 & 0.825 & \\
\hline 13 & Water pump & \multirow{4}{*}{$5-32$} & $5-10$ & 2 & 0.1875 & \multirow{4}{*}{1.5} \\
\hline 14 & Water pump & & $11-16$ & 2 & 0.1875 & \\
\hline 15 & Water pump & & $17-24$ & 2 & 0.1875 & \\
\hline 16 & Water pump & & $25-32$ & 2 & 0.1875 & \\
\hline 17 & $\begin{array}{l}\text { Vacuum } \\
\text { cleaner }\end{array}$ & $37-48$ & -0 & 4 & 0.185 & \multirow[b]{2}{*}{1.48} \\
\hline 18 & $\begin{array}{l}\text { Vacuum } \\
\text { cleaner }\end{array}$ & $57-68$ & - & 4 & 0.185 & \\
\hline 19 & Dryer & $49-64$ & - & 4 & variable & 5.5 \\
\hline 20 & $\begin{array}{l}\text { Coffee } \\
\text { maker }\end{array}$ & $25-32$ & - & 4 & variable & 0.35 \\
\hline 21 & Range top & $37-48$ & - & 4 & variable & 1.6 \\
\hline 22 & $\begin{array}{c}\text { Microwave } \\
\text { oven }\end{array}$ & $69-80$ & - & 4 & variable & 0.8 \\
\hline 23 & Iron box & $77-96$ & - & 4 & variable & 1.2 \\
\hline 24 & Toaster & $25-32$ & - & 2 & variable & 0.55 \\
\hline 25 & $\begin{array}{c}\text { Toaster } \\
\text { oven }\end{array}$ & $69-80$ & - & 2 & variable & 0.75 \\
\hline 26 & $\begin{array}{c}\text { Oven } \\
\text { cleaner }\end{array}$ & $49-64$ & - & 2 & variable & 1.75 \\
\hline 27 & $\begin{array}{c}\text { Washing } \\
\mathrm{m} / \mathrm{c}\end{array}$ & $33-48$ & - & 6 & variable & 0.9975 \\
\hline 28 & Dish washer & $77-96$ & - & 6 & variable & 1.8 \\
\hline 29 & Oven & $37-48$ & - & 6 & variable & 5.25 \\
\hline
\end{tabular}

Table 2. Parameters used for the proposed optimization approach

\begin{tabular}{|c|c|c|c|}
\hline Parameter & Value & Parameter & Value \\
\hline $\mathrm{n}$ & 29 & $\mathrm{~N}_{\mathrm{p}}$ & 500 \\
\hline$\lambda$ & 1.5 & $\mathrm{I}$ & 25 \\
\hline$\gamma_{h}$ & 1 & $\mathrm{R}$ & 0.05 \\
\hline
\end{tabular}




\section{B. Result analysis with RTP-IBR}

Now, the impact of RTP-IBR pricing scheme on the various energy scheduling parameters is analyzed. For the simulation, RTP has been taken from the Ameren Illinois Power Company and date ranges from 01-07-2016 to 31-08-2016 [36]. The simulation results for electricity consumption cost and PAR with RTP-IBR are shown in Figure. 4 and Figure 5.

If the main aim is only to reduce the electricity consumption cost, then during simulation of the problem, we assume $\delta_{a}=1$. From the results of Figure. 4, it is noted that the average daily electricity consumption cost without energy scheduling is 72.54 cents for two months, while it is only 52.19 cents with the proposed energy scheduling with RTP-IBR pricing scheme by considering the energy generated by the PV panels. It means that there is a decrement of $28.05 \%$ (Table 3) in the electricity consumption cost after scheduling the home appliances with the proposed approach. The results of Figure 5 show the impact of our energy scheduling approach on the PAR value of the power. The average value of PAR reduces from 5.85 to 5.12 after the scheduling of the appliances with the decrement of about $12.48 \%$. By these results, it can be concluded that the electricity consumption cost and PAR value have been effectively reduced by using our proposed approach by considering the renewable energy generated by the PV panels. The results of energy consumption cost and PAR value with and without energy scheduling and without considering renewable energy source can be seen in Table 3.

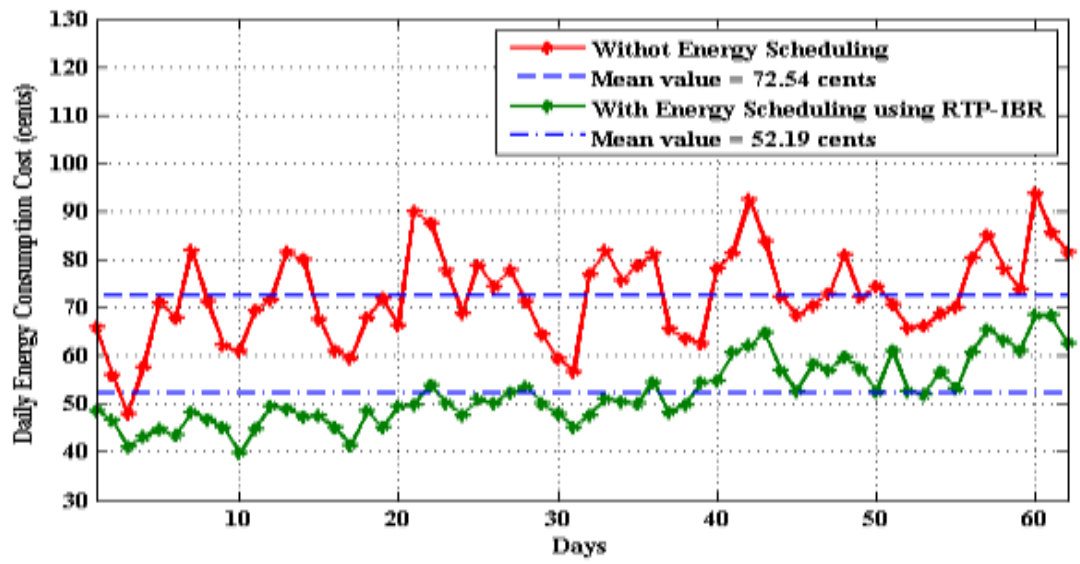

Figure 4. Electricity Cost with and without Energy Scheduling

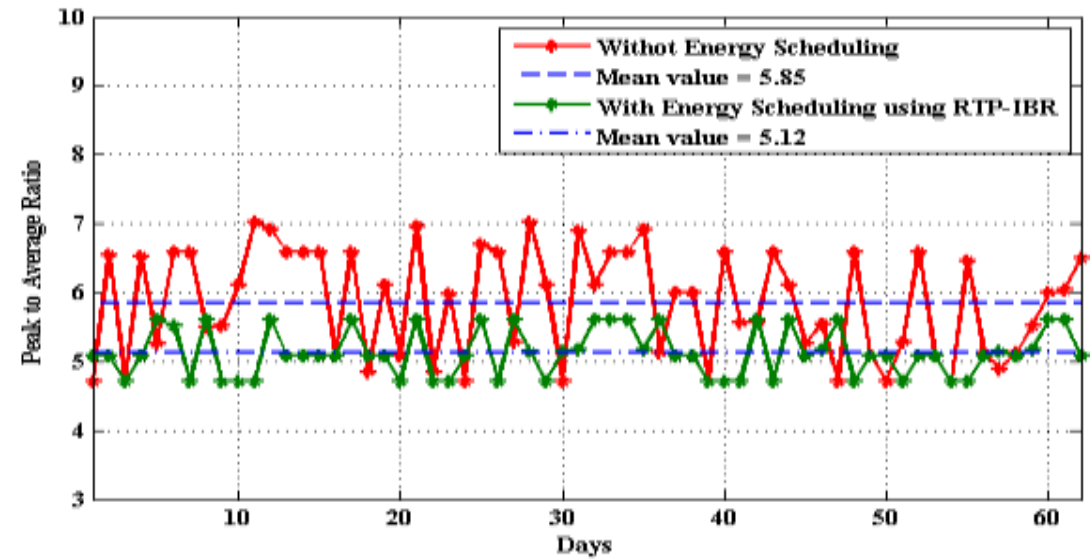

Figure 5. Peak to Average Power ratio with and without Energy Scheduling 
In Figure 6, result of PAR of power is shown with RTP scheme and RTP-IBR pricing scheme. From the Figure, it is clear that with the energy scheduling under RTP-IBR pricing scheme the PAR decreases from 6.96 to 5.12 against the energy scheduling under RTP scheme. The RTP scheme sometimes may lead to high energy demand peaks during energy scheduling, which may cause serious problems in the system. Total $26.44 \%$ (Table-3) decrement is achieved in PAR value of the power with the use of RTP-IBR scheme against RTP scheme. It shows the effectiveness of RTP-IBR pricing scheme over the RTP scheme.

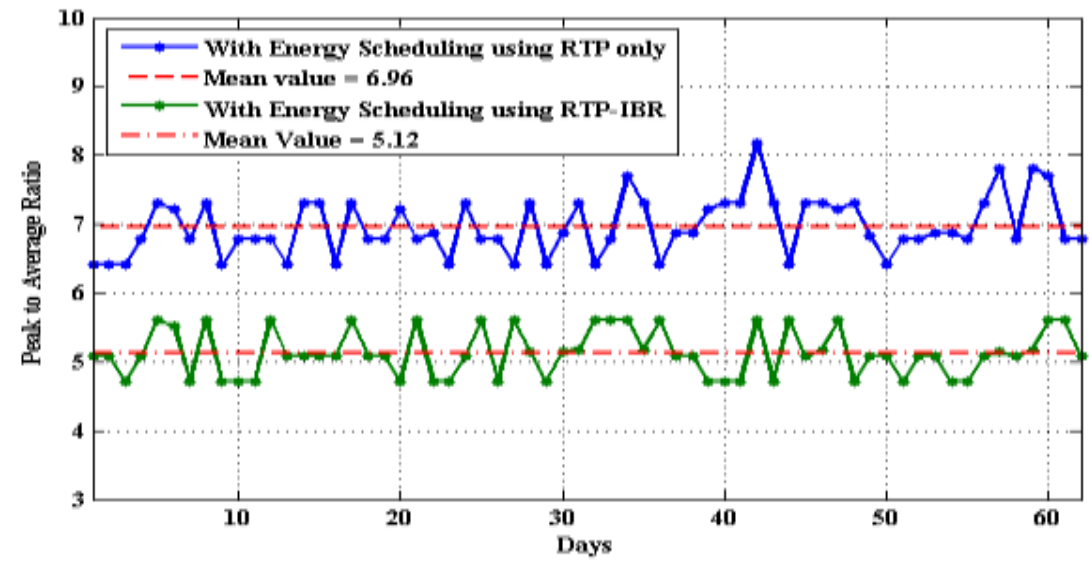

Figure 6. Peak to Average Power ratio comparison with RTP and RTP-IBR

Now the effect of RTP-IBR on the energy demand peaks can be analyzed. Figure. 7 shows the RTP profile on 10-07-2016 in the USA. Figure 8 shows the energy demand peaks achieved without energy scheduling and with energy scheduling under RTP scheme by considering the local renewable energy generated by the PV panels. User may get lower electricity consumption cost with RTP scheme as compared to without energy scheduling but it may also cause high energy demand peaks during low price time. However, the high energy demand peaks disappear due to the effect of two level price of the considered RTP-IBR scheme in Figure 9. This again shows the effectiveness of RTP-IBR scheme over RTP scheme.

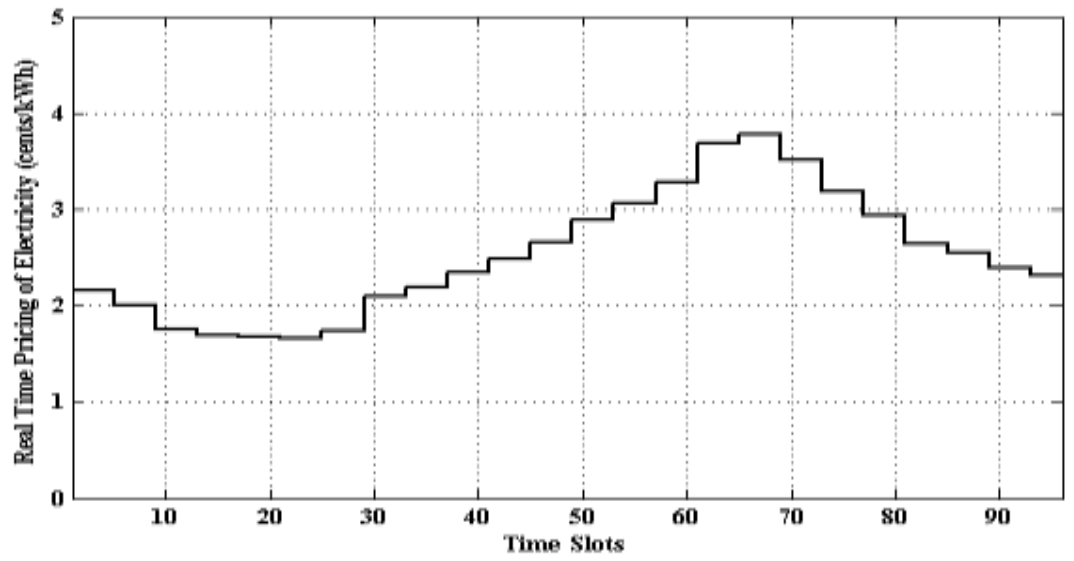

Figure 7. Real Time Price on 10-07-2016 in USA 


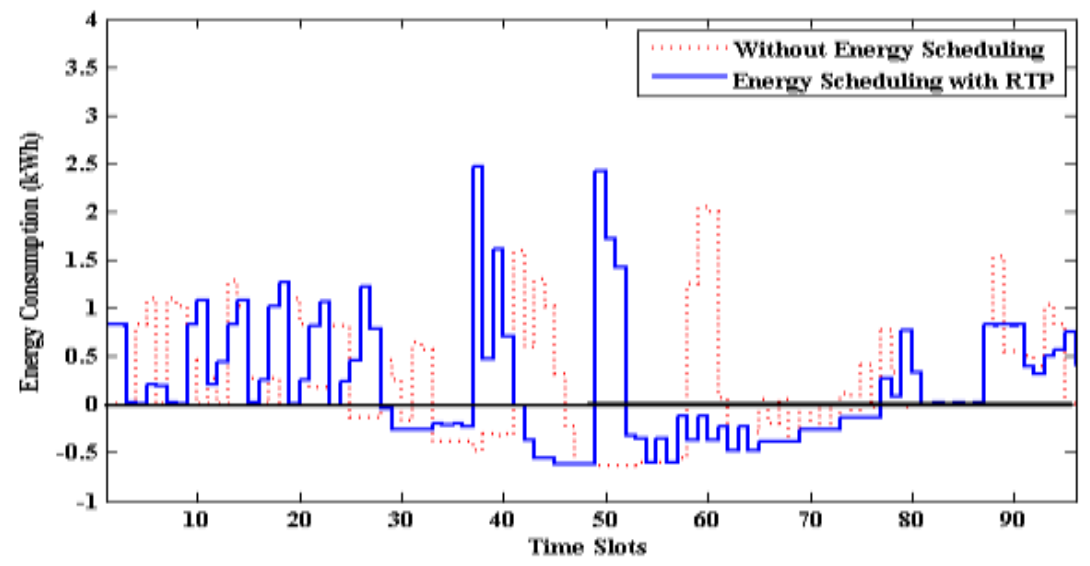

Figure 8. Energy consumption profile with and without energy scheduling under RTP

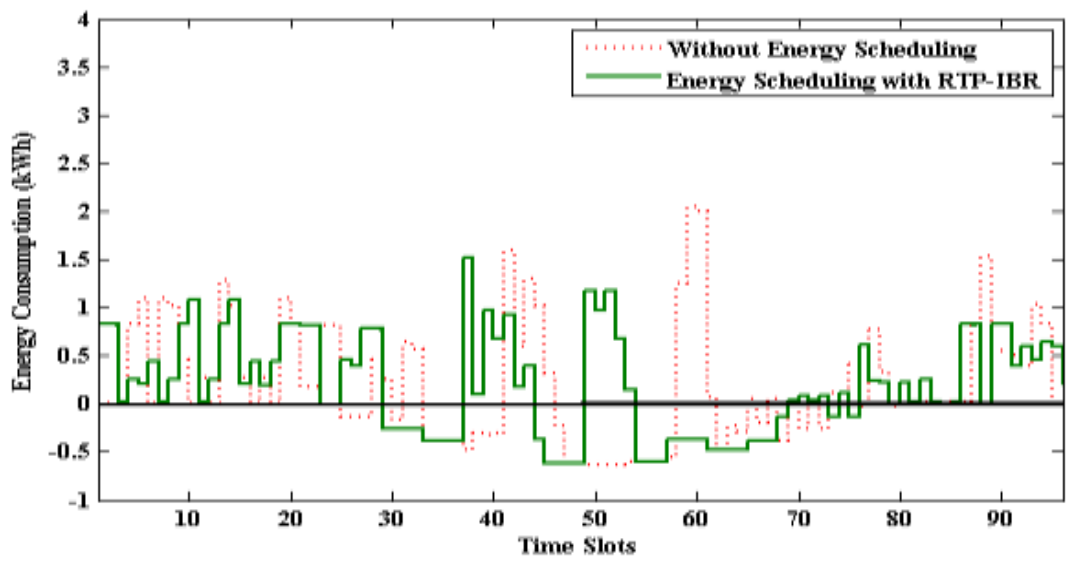

Figure 9. Energy consumption profile with and without energy scheduling under RTP-IBR

To verify the effectiveness of PIO for the solution of energy scheduling problem, the simulation results achieved by PIO are compared with the results achieved by PSO. For PSO optimization, the population size of each generation, $\mathrm{N}_{\mathrm{p}}$ is 500 . The optimization algorithm runs for $\mathrm{I}=25$ iterations. Table 3 shows the results of various scheduling parameters achieved by using both the algorithms. It is found that the cost of energy consumption after scheduling the appliances reduces by $20.73 \%$ using PSO, while it reduces by $28.05 \%$ using PIO. Reduction in PAR value after the energy scheduling is only $8.21 \%$ using PSO, while it reduces by $12.48 \%$ using PIO. On the other hand, the PAR value reduces only by $17.64 \%$ after scheduling by PSO under RTP-IBR scheme with respect to the scheduling under RTP scheme. While in case of PIO, it reduces by $26.44 \%$. The high difference in the percentage change value in this case is due to the effectiveness of PIO on the PAR value achieved after scheduling under RTP-IBR. So with all these analysis, It can be said that the PIO gives better results than PSO on the solution energy scheduling problem. 
Table 3. Comparison of simulation results with PIO and PSO

\begin{tabular}{|c|c|c|c|c|}
\hline \multicolumn{2}{|c|}{ Simulation Approach } & \multicolumn{2}{|c|}{ PIO } & PSO \\
\cline { 3 - 5 } \multirow{2}{*}{$\begin{array}{c}\text { Electricity } \\
\text { Consumption Cost } \\
\text { (cents) }\end{array}$} & $\begin{array}{c}\text { Without } \\
\text { Scheduling }\end{array}$ & 164.02 & 72.54 & 72.54 \\
\cline { 2 - 5 } & $\begin{array}{c}\text { Scheduling with } \\
\text { RTP-IBR }\end{array}$ & 139.48 & 52.19 & 57.50 \\
\cline { 2 - 5 } & $\begin{array}{c}\text { Percentage } \\
\text { change }\end{array}$ & $14.96 \%$ & $28.05 \%$ & $20.73 \%$ \\
\hline \multirow{2}{*}{$\begin{array}{c}\text { Peak to Average } \\
\text { Ratio }\end{array}$} & $\begin{array}{c}\text { Without } \\
\text { Scheduling }\end{array}$ & 5.85 & 5.85 & 5.85 \\
\cline { 2 - 5 } & $\begin{array}{c}\text { Scheduling with } \\
\text { RTP-IBR }\end{array}$ & 5.34 & 5.12 & 5.37 \\
\cline { 2 - 5 } & $\begin{array}{c}\text { Percentage } \\
\text { change }\end{array}$ & $8.72 \%$ & $12.48 \%$ & $8.21 \%$ \\
\hline \multirow{2}{*}{$\begin{array}{c}\text { Peak to Average } \\
\text { Ratio }\end{array}$} & $\begin{array}{c}\text { Scheduling with } \\
\text { RTP }\end{array}$ & 6.96 & 6.96 & 6.52 \\
\cline { 2 - 5 } & $\begin{array}{c}\text { Scheduling with } \\
\text { RTP-IBR }\end{array}$ & 5.34 & 5.12 & 5.37 \\
\cline { 2 - 5 } & $\begin{array}{c}\text { Percentage } \\
\text { change }\end{array}$ & $23.28 \%$ & $26.44 \%$ & $17.64 \%$ \\
\hline
\end{tabular}

\section{Conclusion}

In this paper, we first discussed the detailed architecture of EMS. In this EMS, the interruptible and uninterruptible appliances at home have been included for the energy scheduling purpose. Along with this, the model of rooftop PV panel has also been presented in the paper to consider a distributed renewable energy source. The objective function has been formulated to achieve the optimal solution of the energy consumption cost and the delay cost. The formulated problem has been solved by using the PIO algorithm under DR program based on RTP-IBR pricing scheme. Here, it is also concluded that the role of control parameter $\delta_{a}$ is very important in our proposed model of energy scheduling. By adjusting the value of $\delta_{a}$, the consumer may decide, whether he wants a minimum electricity bill or maximum comfort level. From the results, it has been found that the cost of electricity consumption has been successfully minimized for $\delta_{a}=1$ and the comfort level of the user can also be maintained by adjusting the value of $\delta_{a}$. Along with this, the PAR value has been reduced and maintained within the satisfactory limits, because of the consumer participation in the DR programs. The effectiveness of the results achieved by using the PIO algorithm has been verified by comparing the results achieved by using the PSO algorithm. The assumption made in this paper can be relaxed in the future work. Priorities for different appliances can be set during the energy scheduling. With all these positive arguments, we can say that our proposed approach for the solution of energy scheduling problem of the interruptible and the uninterruptible appliances under DR program can be a reliable method for future EMS at home in the environment of smart grid.

\section{References}

[1]. X. Fang, S. Misra, G. Xue and D. Yang, "Smart Grid - The New and Improved Power Grid: A Survey," in IEEE Communications Surveys \& Tutorials, vol. 14, no. 4, pp. 944980, Fourth Quarter 2012.

[2]. A. H. Mohsenian-Rad, V. W. S. Wong, J. Jatskevich, R. Schober and A. Leon-Garcia, "Autonomous Demand-Side Management Based on Game-Theoretic Energy Consumption Scheduling for the Future Smart Grid," in IEEE Transactions on Smart Grid, vol. 1, no. 3, pp. 320-331, Dec. 2010. 
[3]. P. Palensky and D. Dietrich, "Demand Side Management: Demand Response, Intelligent Energy Systems, and Smart Loads," in IEEE Transactions on Industrial Informatics, vol. 7, no. 3, pp. 381-388, Aug. 2011.

[4]. M.M. Eissa, "Demand side management program evaluation based on industrial and commercial field data," Energy Policy, Volume 39, Issue 10, 2011, Pages 5961-5969.

[5]. P. P. Varaiya, F. F. Wu and J. W. Bialek, "Smart Operation of Smart Grid: Risk-Limiting Dispatch," in Proceedings of the IEEE, vol. 99, no. 1, pp. 40-57, Jan. 2011.

[6]. A. Iwayemi, P. Yi, X. Dong and C. Zhou, "Knowing when to act: an optimal stopping method for smart grid demand response," in IEEE Network, vol. 25, no. 5, pp. 44-49, September-October 2011.

[7]. U.S. Dept. Energy, Benefits of Demand Response in Electricity Markets and Recommendations for Achieving Them, Washington, DC, USA, report to the United States Congress, Feb. 2006.

[8]. D. T. Nguyen, M. Negnevitsky, and M. de Groot, "Pool-based demand response exchange concept and modeling," IEEE Trans. Power Syst., vol. 26, no. 3, pp. 1677-1685, Aug. 2011.

[9]. Q. Dong, L. Yu, W. Z. Song, L. Tong, and S. Tang, "Distributed demand and response algorithm for optimizing social-welfare in smart grid," in Proc. 26th IEEE IPDPS, Shanghai, China, May 21-25, 2012, pp. 1228-1239.

[10]. I. Koutsopoulos and L. Tassiulas, "Optimal control policies for power demand scheduling in the smart grid,” IEEE J. Sel. Areas Commun., vol. 30, no. 6, pp. 1049-1060, Jul. 2012.

[11]. K. M. Tsui and S. C. Chan, "Demand response optimization for smart home scheduling under real-time pricing," IEEE Trans. Smart Grid, vol. 3, no. 4, pp. 1812-1821, 2012

[12]. M. Alizadeh, T. H. Chang, A. Scaglione, C. Chen, and S. Kishore, "The emergence of deferrable energy requests and a greener future: What stands in the way?," in Proceedings of the 5th International Symposium on Communications, Control and Signal Processing, IEEE, Rome, Italy, 2012

[13]. A. Schulke, J. Bauknecht, and J. Haussler, "Power demand shifting with smart consumers: A platform for power grid friendly consumption control strategies," in Smart Grid Communications (Smart Grid Comm), First IEEE International Conference, 2010, pp. 437-442

[14]. Y.T. Huang, H.J. Tian, L. Wang, "Demand response for home energy management system," International Journal of Electr. Power Energy Syst. 73 (2015) 448-455

[15]. R. Missaoui, H. Joumaa, S. Ploix, S. Bacha, "Managing energy smart homes according to energy prices: analysis of a building energy management system," Energy Buildings. 71 (2014) 155-167

[16]. Q. Li Ping, Y.J.A. Zhang, H. Jianwei, W. Yuan, "Demand response management via realtime electricity price control in smart grids," IEEE Journal on selected areas in communications, 31 (2013) 1268-1280

[17]. D. B. Vilar and C. de Mattos Affonso, "Residential energy management system with photovoltaic generation using simulated annealing," 2016 13th International Conference on the European Energy Market (EEM), Porto, 2016, pp. 1-6

[18]. C. H. Antunes, A. Soares and Á. Gomes, "An energy management system for residential demand response based on multiobjective optimization," 2016 IEEE Smart Energy Grid Engineering (SEGE), Oshawa, ON, 2016, pp. 90-94.

[19]. Hamed Shakouri G., Aliyeh Kazemi, Multi-objective cost-load optimization for demand side management of a residential area in smart grids, Sustainable Cities and Society, Volume 32, 2017, Pages 171-180

[20]. Z. Chen, L. Wu, and Y. Fu, "Real-time price-based demand response management for residential appliances via stochastic optimization and robust optimization," IEEE Trans. Smart Grid, vol. 3, no. 4, pp. 1822-1831, Dec. 2012

[21]. M. Restegar, M. F. Firuzabad, and F. Aminifar, "Load commitment in a smart home," Appl. Energy, vol. 96, pp. 45-54, Aug. 2012 
[22]. S. Shao, M. Pipattanasomporn, and S. Rahman, "Demand response as a load shaping tool in an intelligent grid with electric vehicles," IEEE Trans. Smart Grid, vol. 2, no. 4, pp. 624631, Dec. 2011

[23]. M. Kuzlu, M. Pipattanasomporn, and S. Rahman, "Hardware demonstration of a home energy management system for demand response applications," IEEE Trans. Smart Grid, vol. 3, no. 4, pp. 1704-1711, Dec. 2012

[24]. M. Pipattanasomporn, M. Kuzlu, and S. Rahman, "An algorithm for intelligent home energy management and demand response analysis," IEEE Trans. Smart Grid, vol. 3, no. 4, pp. 2166-2173, Dec. 2012

[25]. A. H. Mohsenian-Rad and A. Leon-Garcia, "Optimal residential load control w/ price prediction in real-time electricity pricing environments," IEEE Trans. Smart Grid, vol. 1, pp. 120-133, Sep. 2010

[26]. P. Du and N. Lu, "Appliance commitment for household load scheduling," IEEE Trans. Smart Grid, vol. 2, pp. 411-419, Jun. 2011

[27]. H.T. Haider, O.H. See and W. Elmenreich, "A review of residential demand response of smart grid," Renewable and Sustainable Energy Reviews 2016;59:166-78

[28]. T. Roy, A. Das and Z. Ni, "Optimization in load scheduling of a residential community using dynamic pricing," 2017 IEEE Power \& Energy Society Innovative Smart Grid Technologies Conference (ISGT), Washington, DC, 2017, pp. 1-5

[29]. S. H. Elyas, H. Sadeghian, H. O. Alwan and Z. Wang, "Optimized household demand management with local solar PV generation," 2017 North American Power Symposium (NAPS), Morgantown, WV, USA, 2017, pp. 1-6

[30]. C. Wang, Y. Zhou, B. Jiao, Y. Wang, W. Liu, and D. Wang, "Robust optimization for load scheduling of a smart home with photovoltaic system," Energy Convers. Manage., vol. 102, pp. 247-257, Sep. 2015.

[31]. Z. Zhu, S. Lambotharan, W. H. Chin, and Z. Fan, "A game theoretic optimization framework for home demand management incorporating local energy resources," IEEE Trans. Ind. Informat., vol. 11, no. 2, pp. 353-362, Apr. 2015.

[32]. A. Haurie and C. Andrey, "The economics of electricity dynamic pricing and demand response programs," 2013. Available: www.ordecsys.com/fr/system/files/shared/TOUPremierRapport.pdf

[33]. Solar data. Available: http://rredc.nrel.gov/solar/old_data/nsrdb/1991-2005/tmy3/

[34]. Haibin Duan, Peixin Qiao,"Pigeon-inspired optimization: a new swarm intelligence optimizer for air robot path planning", International Journal of Intelligent Computing and Cybernetics, Vol. 7 Iss 1 pp. 24 - 37, 2014.

[35]. Inclining Block Rate in British Columbia Hydro Co. [Online]. Available:http://www. bchydro.com/youraccount/con-tent/resi-dential_rates.jsp

[36]. Real-time pricing for residential customers, Ameren Illinois Power Co. [Online]. Available: https://www.ameren.com/account/retail-energy 


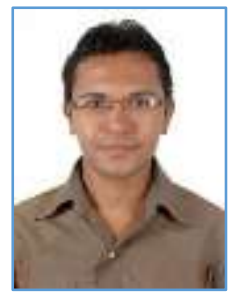

Sandeep Kakran (b.1989) received his B.Tech degree from Uttarakhand Technical University, Dehradun in July 2010 in Electrical Engineering, M.E. degree from Punjab Engineering College University of Technology, Chandigarh in July 2012 in Electrical Engineering and Ph.D. from National Institute of Technology Kurukshetra, India in 2019 in Electrical Engineering. He has worked as Assistant Professor at Electrical \& Electronics Department in Sharda University, Greater Noida for one year starting in 2012 and presently working as Assistant Professor at Department of Electrical Engineering in National Institute of Technology, Kurukshetra, India since 2013.

He has been teaching subjects in the area of power system technology for nearly 6 Years. His research interests are in the area of microgrid, real-time pricing, demand side energy management, demand response and grid integration of renewable energy.

He has guided 4 M.Tech dissertations until now. He has to his credit 8 Journal and 5 Conference publications. He is member of IEEE Power and Energy Society.

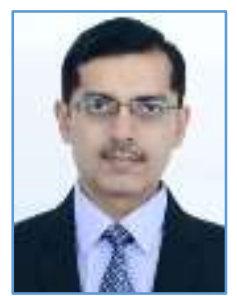

Saurabh Chanana (b.1975) received his B.Tech., M.Tech. and Ph.D. from National Institute of Technology Kurukshetra, India in 1996, 2002, and 2011 respectively.

He has worked with DLF Universal Ltd. for one year starting in 1996. He joined National Institute of Technology Kurukshetra as Lecturer in 1998 and is presently working as Associate Professor at Department of Electrical Engineering there.

He has been teaching subjects in the area of power system technology for nearly 20 Years. His research interests are in the area of power system restructuring, real-time pricing, demand response and grid integration of renewable energy.

He has guided $27 \mathrm{M}$.Tech dissertations and $3 \mathrm{Ph} . \mathrm{D}$. thesis until now. One of the M. Tech dissertations guided by him has received prestigious POSOCO Power System Award in 2015. He has to his credit one book chapter, 24 Journal and 43 Conference publications. He is member of IEEE Power and Energy Society and life member of Indian Society of Technical Education. 